\title{
TotalTrack video intubating laryngeal mask in super-obese patients - series of cases
}

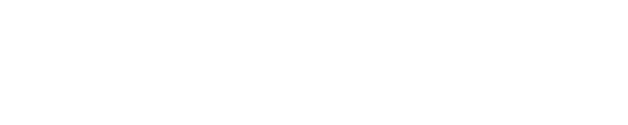

\section{Tomasz Gaszynski}

Department of Emergency and Disaster Medicine, Medical University of Lodz, Lodz, Poland
Correspondence: Tomasz Gaszynski Department of Emergency and Disaster Medicine, Medical University of Lodz, ul. Kopcinskiego 22, 90-I53 Lodz, Poland Tel +48426783748 Email tomasz.gaszynski@umed.lodz.pl
Background: Super-obese patients are at increased risk of difficult mask ventilation and difficult intubation. Therefore, devices that allow for simultaneous ventilation/oxygenation during attempts to visualize the entrance to the larynx, increase patient safety. TotalTrack video intubating laryngeal mask is a new device that allows for ventilation during intubation efforts.

Patients and methods: Twenty-four super-obese patients (body mass index $>50 \mathrm{~kg} / \mathrm{m}^{2}$ ) were divided into two subgroups: intubation efforts using 1) TotalTrack and 2) Macintosh blade standard laryngoscope in induction of general anesthesia. Visualization and successful intubation was evaluated for both groups with ventilation and post-mask complications additionally evaluated for TotalTrack.

Results: In all cases in the TotalTrack group, the Cormack-Lehane score was 1, ventilation and intubation was successful in 11/12 patients. No hypoxia during intubation efforts was recorded. No serious complications of use of TotalTrack were observed. In the Macintosh blade laryngoscope group, all patients were intubated, but the Cormack-Lehane score was 2 in four cases, and 3 in three cases.

Conclusion: TotalTrack video intubating laryngeal mask is a device that allows for better visualization of the larynx compared to the standard Macintosh blade laryngoscope, it provides effective ventilation/oxygenation and intubation in super-obese patients.

Keywords: super-obese, intubation, ventilation, laryngeal mask, standard laryngoscope, video laryngoscope

\section{Background}

Super-obesity criterion is when body mass index (BMI) exceeds $50 \mathrm{~kg} / \mathrm{m}^{2}{ }^{1}$ Super-obesity is one of the risk factors influencing probability of difficult mask ventilation and difficult intubation. ${ }^{2}$ Super-obese patients should be intubated either with fiberscope awake intubation or with video laryngoscopes. ${ }^{3}$ TotalTrack video intubating laryngeal mask (MedCom Flow, Barcelona, Spain) is a new device which enables ventilation (and oxygenation) during attempts to visualize the entrance to the larynx and intubate the patient. Construction of this device is based on a laryngeal mask combined with a video laryngoscope with endotracheal tube channel (Figure 1). The possibility of oxygenation of the patient during attempts of visualization of the larynx and intubation is especially important in super-obese patients, who desaturate very fast because of small oxygen reserves. ${ }^{4}$ In a prospective observational study, we decided to evaluate the clinical use of TotalTrack video intubating laryngeal mask compared to the standard Macintosh blade laryngoscope (MCL) in super-obese patients (Medical University of Lodz Ethics Committee Approval RNN/363/13/KB). Patient consent was obtained for publication. 


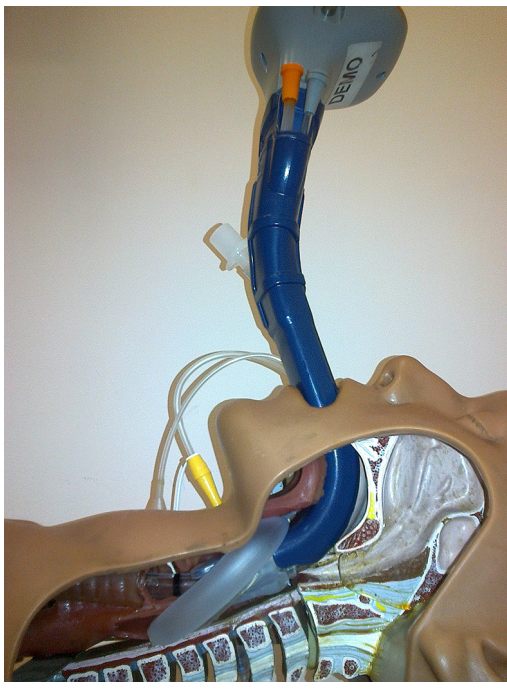

Figure I TotalTrack video intubating laryngeal mask.

\section{Patients and methods}

Twenty-four super-obese patients were enrolled in this observational study. Demographic data are presented in Table 1. Patients were scheduled for elective bariatric surgery. Anesthesia management was based on guidelines of the European Society of Perioperative Care of the Obese Patient (www.espcop.org). After effective preoxygenation, general anesthesia was induced with intravenous dose-adjusted propofol for bispectral index (BIS) monitoring (BIS $<60$ ).

In the TotalTrack group, the device was introduced and ventilation was commenced (Figures 2 and 3 ). If ventilation was possible, the patient received a muscle relaxant (rocuronium) at a dose of $0.6 \mathrm{mg} / \mathrm{kg}$ of ideal body weight. Endotracheal intubation was performed after visualization of the entrance of the larynx (Figure 4). Visualization of the larynx was assessed using the Cormack-Lehane (CL) scale. After ensuring the proper positioning of the endotracheal tube, the laryngeal mask was removed. Time to laryngeal mask placement, leak pressure of ventilation, visualization of entrance to larynx, ease of intubation, and signs of blood on the mask after removal (bloodstreams) were recorded. Leak pressure was measured using the following method: oxygen flow $3 \mathrm{~L} / \mathrm{min}$ and closing valve with increasing pressure until air leak around the mask can be heard.

Table I Demographic data of the groups observed

\begin{tabular}{lll}
\hline Parameter & $\begin{array}{l}\text { TotalTrack } \\
\text { group }(\mathbf{n}=\mathbf{I 2})\end{array}$ & $\begin{array}{l}\text { Macintosh blade } \\
\text { laryngoscope } \\
\text { group }(\mathbf{n}=\mathbf{I 2})\end{array}$ \\
\hline Age (years) & $46.3 \pm 9$ & $39.8 \pm 10.9$ \\
Weight $(\mathrm{kg})$ & $155.4 \pm 20$ & $149.7 \pm 19.4$ \\
Height $(\mathrm{cm})$ & $166.4 \pm 9$ & $166.5 \pm 8.2$ \\
Body mass index $\left(\mathrm{kg} / \mathrm{m}^{2}\right)$ & $55.62 \pm 4.54$ & $53.8 \pm 3.5$ \\
\hline
\end{tabular}

Note: $P>0.05$.

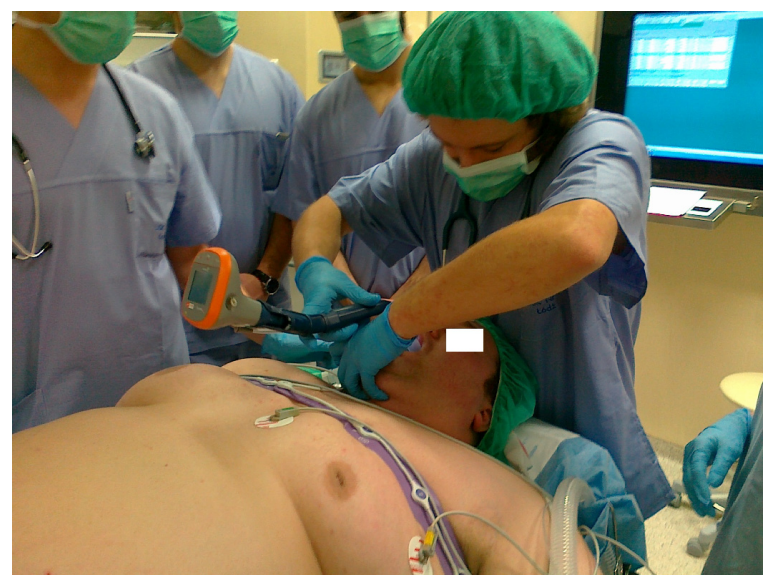

Figure 2 TotalTrack insertion.

In the MCL group, anesthesia was commenced the same way. After ensuring face mask ventilation, a muscle relaxant was administrated and after achieving 100\% muscle relaxation, intubation efforts were commenced. Visualization of the larynx was assessed by the CL scale.

Statistical significance was set at 5\%. Statistical analysis was performed between groups using independent samples Student's $t$-test with double samples assuming unequal variations. All statistical tests were performed with Microsoft Office Excel.

\section{Results}

There was no difference between groups regarding demographic data (Table 1). Results of observation of ventilation and intubation possibilities are shown in Table 2. In the MCL group, all patients were intubated during the first attempt, but CL score was 2 in four cases, and 3 in three cases. In the TotalTrack group, CL score was 1 in 11/12 cases. In one case, ventilation was not effective because of a persistent leak, but fast intubation through TotalTrack

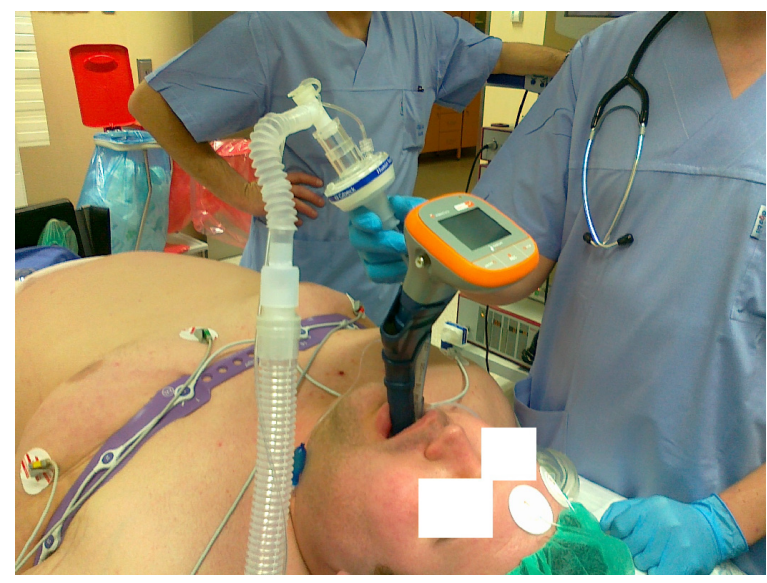

Figure 3 Ventilation through TotalTrack. 

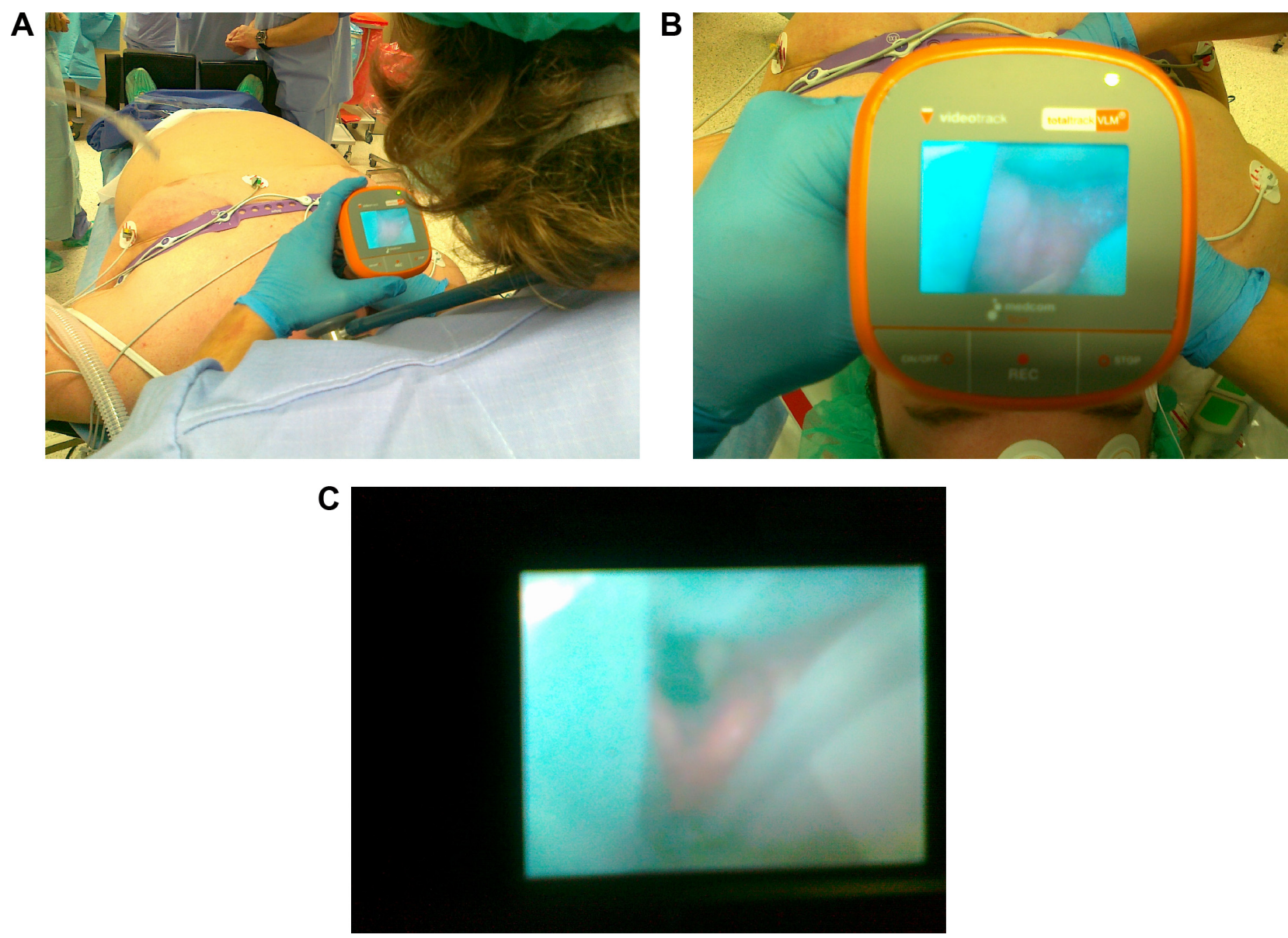

Figure 4 Visualization of the entrance to the larynx using TotalTrack.

Notes: (A) Holding the TotalTrack device for visualization of larynx; (B) view observed by operator of device; (C) picture of entrance to larynx recorded by device.

was possible. No episodes of hypoxia were observed during use of the TotalTrack. In all cases, visualization of the entrance to the larynx was good (except for one case with a technical problem - gel obscuring view) even though all patients showed signs of possible difficult intubation - neck circumflex $>42 \mathrm{~cm}$.

\section{Discussion}

In the literature, there is a lack of papers on airway management evaluation in super-obese patients. First, we evaluate

Table 2 Results of the observation

\begin{tabular}{lll}
\hline Parameter & $\begin{array}{l}\text { TotalTrack } \\
\text { group }\end{array}$ & $\begin{array}{l}\text { Macintosh blade } \\
\text { laryngoscope } \\
\text { group }\end{array}$ \\
\hline Insertion time $(\mathrm{s})$ & $9 \pm 3$ & $7.7 \pm 3.6$ \\
Effective ventilation $(\mathrm{n})$ & $\mathrm{II} / \mathrm{I2}$ & $\mathrm{NA}$ \\
Effective intubation $(\mathrm{n})$ & $\mathrm{II} / \mathrm{I} 2$ & $\mathrm{I} 2 / \mathrm{I} 2$ \\
Laryngeal view $(\mathrm{CL} \mathrm{score} \mathrm{I} / 2 / 3 / 4)$ & $\mathrm{II} / \mathrm{I} / 0 / 0$ & $5 / 4 / 3 / 0$ \\
Leak pressure $\left(\mathrm{cm} \mathrm{H}_{2} \mathrm{O}\right)$ & $2 \mathrm{I} \pm 6$ & $\mathrm{NA}$ \\
Bloodstreams on mask removal $(\mathrm{n})$ & $\mathrm{I} / 12$ & $\mathrm{NA}$ \\
\hline
\end{tabular}

Abbreviations: CL, Cormack-Lehane; NA, not applicable. video-assisted intubation in this group of patients. Simultaneous ventilation/oxygenation during attempts of visualization of the entrance to the larynx increases patient safety. In superobese patients compared to obese patients, hypoxia occurred more often during intubation, regardless of the technique used. ${ }^{5}$ There are no available studies on TotalTrack in obese patients; however, there have been studies on a similar device on the market - Ctrach intubating laryngeal mask airway. In Yousef et al's study, the authors concluded that due to the possibility of ventilation during intubation efforts when using the Ctrach intubating laryngeal mask airway, there were no episodes of desaturation in obese patients, compared to using the Glidescope video laryngoscope ${ }^{6}$ or standard MCL, ${ }^{6,7}$ during which several cases of hypoxia occurred. Even when the AirTraq optical laryngoscope was used in obese patients, hypoxia was observed during some intubation attempts. ${ }^{8}$ During our observation, there were no episodes of hypoxia in super-obese patients when TotalTrack was used.

With increasing BMI, the probability of difficult intubation is increased. ${ }^{9}$ Neck circumference of more than $42 \mathrm{~cm}$ and BMI more than $50 \mathrm{~kg} / \mathrm{m}^{2}$ (super-obese) are independent 
predictors of difficult intubation. ${ }^{10}$ Moreover, male sex and BMI more than $50 \mathrm{~kg} / \mathrm{m}^{2}$ (super-obese) are independent predictors of difficult mask ventilation. ${ }^{10}$ These results show that in case of super-obese patients, it is necessary to be prepared for both difficult mask ventilation and difficult intubation. Therefore, the use of devices providing ventilation during intubation efforts is justified.

TotalTrack video intubating laryngeal mask is similar in construction to the group of video laryngoscopes with an endotracheal tube channel: AirTraq, KingVision, and Pentax AWS. These devices are very effective in obese patients, ${ }^{11}$ similar to other video laryngoscopes. ${ }^{12}$

There have been no studies on super-obese patients regarding airway management. In one retrospective study, Leykin et al did not observe differences in occurrence of difficult intubation between morbidly obese and super-obese patients. ${ }^{1}$ However, they observed a significant difference in post-intubation complications: the rate of damage to teeth was higher in the super-obese group compared to the morbidly obese group ( $6 \%$ vs $1 \%$ ). This suggests that more force was used during attempts of intubation in super-obese patients, so the conditions of intubation were worse.

In our data, we observed a higher percentage of worse visualization of the entrance to the larynx in super-obese compared to morbidly obese patients (CL score 1: $50 \%$ vs 53.7\%; CL score 2: $33.3 \%$ vs $25.4 \%$; CL score 3: $16.7 \%$ vs $13.4 \%$; CL score 4 : $0 \%$ vs $7.5 \%$ in super-obese and morbidly obese patients, respectively). ${ }^{12}$ Dixit et al had similar observations: $44.4 \%$ of super obese patients had incidence of Cormack grades 3 and 4 comparing to $20.4 \%$ in morbidly obese patients. ${ }^{13}$

\section{Conclusion}

TotalTrack video intubating laryngeal mask is a device that allows for better visualization of the larynx compared to standard MCL, and provides effective ventilation/oxygenation and effective intubation in super-obese patients.

\section{Disclosure}

The author reports no conflicts of interest in this work.

\section{References}

1. Leykin Y, Pellis T, Del Mestro E, Marzano B, Fanti G, Brodsky JB. Anesthetic management of morbidly obese and super-morbidly obese patients undergoing bariatric operations: hospital course and outcomes. Obes Surg. 2006;16(12):1563-1569.

2. Gaszynski T, Gaszynska E, Szewczyk T3. Dexmedetomidine for awake intubation and an opioid-free general anesthesia in a superobese patient with suspected difficult intubation. Drug Des Devel Ther. 2014;8:909-912.

3. Pelosi P, Gregoretti C. Perioperative management of obese patients. Best Pract Res Clin Anaesthesiol. 2010;24(2):211-225.

4. Dixon BJ, Dixon JB, Carden JR, et al. Preoxygenation is more effective in the 25 degrees head-up position than in the supine position in severely obese patients: a randomized controlled study. Anesthesiology. 2005;102(6):1110-1115.

5. Yaung J, May J, Johnson K, et al. Airway and anesthetic management in super-morbidly obese patients: measuring outcomes of intubation, ventilation, and oxygenation. American Society of Anesthesiologists congress materials; 2012. Abstract A779. Available from: http://www. asaabstracts.com/strands/asaabstracts/abstract.htm;jsessionid=A4A6C A3853F46CB59CA35020221464C2 year $=2012 \&$ index $=15 \&$ absnum $=$ 4200. Accessed December 16, 2015.

6. Yousef GT, Abdalgalil DA, Ibrahim TH. Orotracheal intubation of morbidly obese patients, comparison of GlideScope ${ }^{\circledR}$ video laryngoscope and the LMA CTrach ${ }^{\mathrm{TM}}$ with direct laryngoscopy. Anesth Essays Res. 2012;6(2):174-179.

7. Dhonneur G, Ndoko SK, Yavchitz A, et al. Tracheal intubation of morbidly obese patients: LMA CTrach vs direct laryngoscopy. $\mathrm{Br}$ J Anaesth. 2006;97(5):742-745.

8. Dhonneur G, Abdi W, Ndoko SK, et al. Video-assisted versus conventional tracheal intubation in morbidly obese patients. Obes Surg. 2009;19(8):1096-1101.

9. Lundstrøm LH, Møller AM, Rosenstock C, Astrup G, Wetterslev J. High body mass index is a weak predictor for difficult and failed tracheal intubation: a cohort study of 91,332 consecutive patients scheduled for direct laryngoscopy registered in the Danish Anesthesia Database. Anesthesiology. 2009;110(2):266-274.

10. Riad W, Vaez MN, Raveendran R, et al. Neck circumference as a predictor of difficult intubation and difficult mask ventilation in morbidly obese patients: A prospective observational study. Eur J Anaesthesiol. Epub 2015 Sep 8.

11. Ndoko SK, Amathieu R, Tual L, et al. Tracheal intubation of morbidly obese patients: a randomized trial comparing performance of Macintosh and Airtraq laryngoscopes. Br J Anaesth. 2008;100(2):263-268.

12. Gaszynski T. Clinical experience with the C-Mac videolaryngoscope in morbidly obese patients. Anaesthesiol Intensive Ther. 2014; 46(1):14-16.

13. Dixit A, Kulshrestha M, Mathews JJ, Bhandari M. Are the obese difficult to intubate? Br J Anaesth. 2014;112(4):770-771.
Therapeutics and Clinical Risk Management

\section{Publish your work in this journal}

Therapeutics and Clinical Risk Management is an international, peerreviewed journal of clinical therapeutics and risk management, focusing on concise rapid reporting of clinical studies in all therapeutic areas, outcomes, safety, and programs for the effective, safe, and sustained use of medicines. This journal is indexed on PubMed Central, CAS,

\section{Dovepress}

EMBase, Scopus and the Elsevier Bibliographic databases. The manuscript management system is completely online and includes a very quick and fair peer-review system, which is all easy to use. Visit $\mathrm{http}: / /$ www.dovepress.com/testimonials.php to read real quotes from published authors. 